\title{
Extrapleural air versus pneumothorax: A close call
}

Dear Editor,

A 28-year-old male sustained head injuries during a road traffic accident 2 months prior. He had been admitted at an outside hospital and managed conservatively for intracranial bleed. He was subsequently tracheostomized and transferred to our hospital in view of new onset subcutaneous emphysema and probable pneumothorax. This apparently happened after an episode of tracheostomy tube block when the patient was vigorously ventilated by bag and mask.

On examination, he had normal vitals with crepitus on palpating the right side of his chest and neck. His chest radiograph [Figure 1] revealed pneumomediastinum and subcutaneous emphysema. His CT chest [Figure 2] showed a small left-sided pneumothorax with pneumomediastinum and air tracking into extrapleural intrathoracic fascia and subcutaneous emphysema.

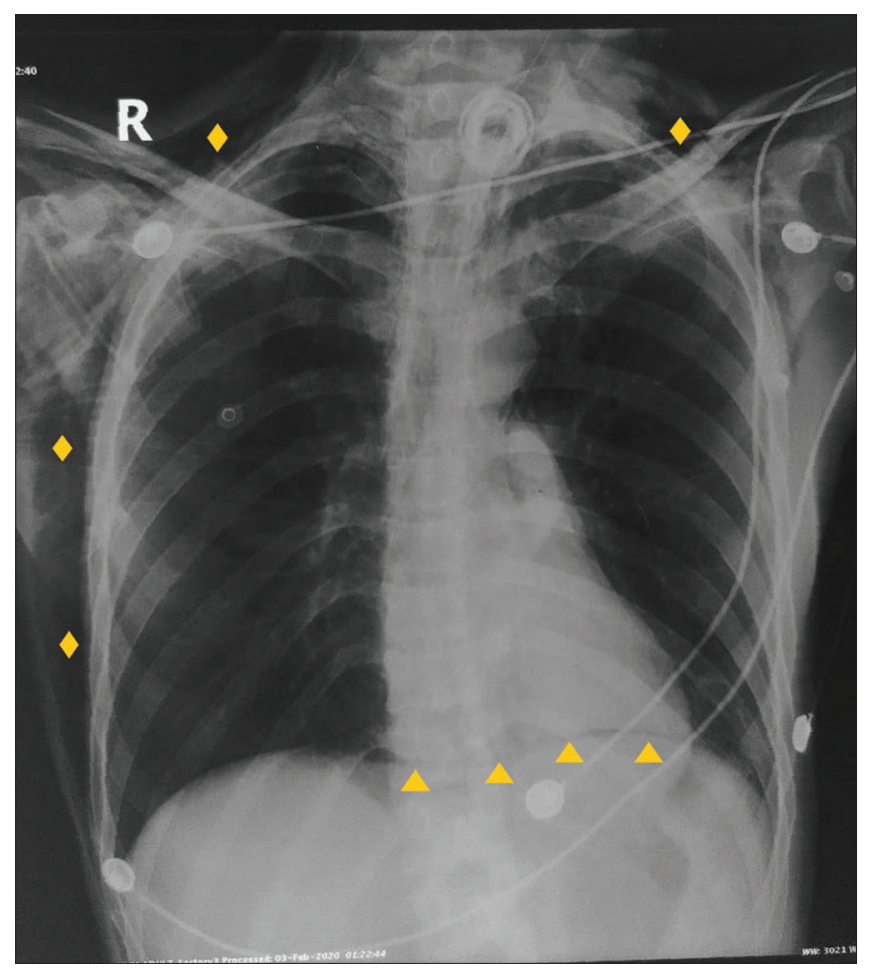

Figure 1: Chest Radiograph demonstrating the continuous diaphragm sign $(\Delta)$ and subcutaneous emphysema $(\diamond)$
Extrapleural intrathoracic air extends as a longitudinal column or remains trapped between fascial planes [Figure 3], and closely resembles a loculated pneumothorax. On keen observation, it can be noted that extrapleural air lies outside a wavy, thick pleural line while in pneumothorax a regular, thin visceral pleura separates the lung margin from the air. This can be difficult to delineate on a chest radiograph and a CT aids in further differentiation between extrapleural air and intrapleural pneumothorax ${ }^{[1,2]}$ as mentioned in Table 1.

In our case, it was hypothesized that vigorous bag masking had caused alveolar rupture leading to pneumomediastinum. ${ }^{[3]}$ This can be explained by Macklin effect, ${ }^{[4]}$ wherein the air tracks along the pulmonary vasculature towards the mediastinum due to negative intrathoracic pressure resulting in a pneumomediastinum and subsequently a subcutaneous emphysema.

Usually the extra-pleural air is absorbed slowly resulting in spontaneous remission. It is necessary to differentiate it from a pneumothorax as the latter often requires placement of an intercostal tube drainage. As the pneumothorax on the left side was small in size with no respiratory or hemodynamic compromise, conservative treatment was continued with which the patient improved.

Extrapleural air is closely related to pneumomediastinum and it has to be differentiated from intrapleural pneumothorax

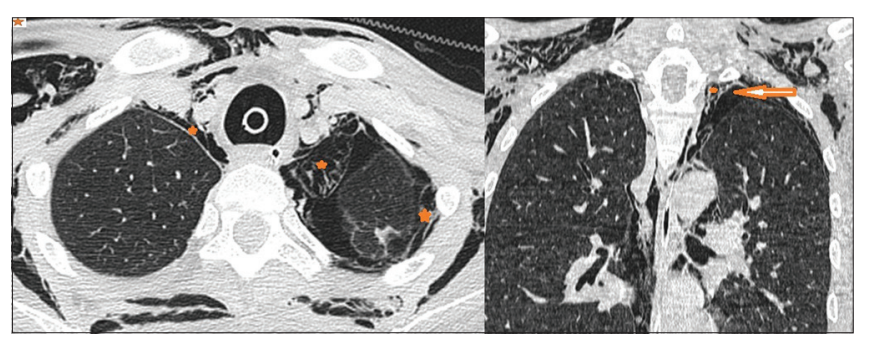

Figure 2: Axial and coronal reconstructions (lung window) thorax reveal presence of extrapleural air $\left({ }^{*}\right)$ with internal septations, with pneumothorax (arrow) outlining the lung margin. There is extensive subcutaneous emphysema along the chest wall

Table 1: Differentiating features between extrapleural air and pneumothorax

\begin{tabular}{|c|c|c|}
\hline & Extra-pleural air or pneumothorax & Intra-pleural Pneumothorax \\
\hline Change of position of air collection with gravity & Not much change & Usually assumes non-dependent position, unless loculated \\
\hline Streaky lines or networks in the air collections & Present & Usually absent \\
\hline Continuity with pneumomediastinum & $\begin{array}{l}\text { On coronal reconstruction, apical air may be seen to } \\
\text { be continuous with pneumomediastinum }\end{array}$ & The air is confined within the pleural space \\
\hline
\end{tabular}




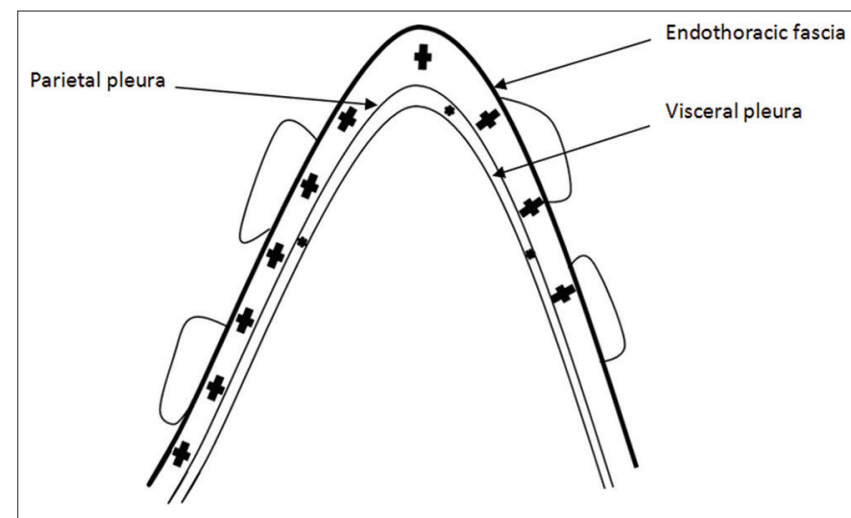

Figure 3: Extrapleural air occupies the space between parietal pleura and endothoracic fascia (marked as ' + ') while pneumothorax occupies the space between parietal and visceral pleura (marked as '*')

as their management is markedly different. Clinicians and radiologists taking care of critically ill patients should know about this entity and its contrasting features from pneumothorax.

\section{Declaration of patient consent}

The authors certify that they have obtained all appropriate patient consent forms. In the form the patient(s) has/have given his/her/their consent for his/her/their images and other clinical information to be reported in the journal. The patients understand that their names and initials will not be published and due efforts will be made to conceal their identity, but anonymity cannot be guaranteed.

\section{Acknowledgement}

All the residents and faculty members of Unit 1 of department of Medicine.

\section{Financial support and sponsorship}

Nil.

\section{Conflicts of interest}

There are no conflicts of interest.
Animesh Ray, Surabhi Vyas ${ }^{1}$, Aishwarya Ramprasad, Naval Vikram

Departments of Medicine and ${ }^{1}$ Radiology, AlIMS, New Delhi, India.

E-mail: doctoranimeshray@gmail.com

\section{References}

1. Kurihara Y, Nakajima Y, Niimi H, Arakawa H, Ishikawa T. Extrapleural air collections mimicking pneumothorax: Helical CT finding. J Comput Assist Tomogr 1997;21:771-2.

2. Olsson O. Accidental extrapleural pneumothorax. Acta Radiologica 1948;29:117-29.

3. Rozeik C, Kotterer O, Deiningr HK. Pneumothorax simulated by detachment of parietal pleura associated with pneumomediastinum. Eur Radiol 19944:496-9.

4. Ray A. A letter in response to recurrent subcutaneous emphysema in a treated tuberculosis patient: Is there any association? Lung India 2014;31:312-4.

This is an open access journal, and articles are distributed under the terms of the Creative Commons Attribution-NonCommercial-ShareAlike 4.0 License, which allows others to remix, tweak, and build upon the work non-commercially, as long as appropriate credit is given and the new creations are licensed under the identical terms.

\begin{tabular}{|l|l|}
\hline \multicolumn{2}{|c|}{ Access this article online } \\
\hline Quick Response Code: & \\
\hline & Website: \\
\hline & www.ijri.org \\
\cline { 2 - 3 } & DOI: \\
\hline
\end{tabular}

Cite this article as: Ray A, Vyas S, Ramprasad A, Vikram N. Extrapleural air versus pneumothorax: A close call. Indian J Radiol Imaging 2020;30:535-6.

Received: 18-Jun-2020

Accepted: 11-Aug-2020

Revised: 23-Jul-2020

Published: 13-Jan-2021

๑) 2021 Indian Journal of Radiology and Imaging | Published by Wolters Kluwer - Medknow 